\title{
CORPOS E PAPEIS SOCIAIS NO BRASIL NO INÍCIO DO SÉC. XX
}

\author{
BODIES AND SOCIAL ROLES IN BRAZZL AT THE BEGINNING OF THE ZO'H CENTURY
}

\begin{abstract}
RESUMO
O objetivo do presente texto é reunir alguns argumentos sobre a produção de corpos femininos e sua relação com o desempenho de papeis sociais no período compreendido entre a segunda metade do séc. XVIII e início XX. Mais especificamente arrolaremos argumentos de Michel Foucault sobre a produção científica sobre o corpo da mulher a partir do séc. XVIII. Para tanto, a estratégia de histerização do corpo da mulher será nosso principal ponto de reflexão. Em um segundo momento, trataremos de ver como um grupo de intelectuais brasileiras tem refletido sobre a produção desses corpos e sua relação com o desempenho de papeis sociais em nosso contexto até o início do séc. XX.
\end{abstract}

Palavras-chave: Histeria. Corpo da mulher. Poder. Michel Foucault.

\section{ABSTRACT}

The purpose of this text is to gather some arguments about the production of women's bodies and their relation to the performance of social roles in the period between the second half of the 18th century and the beginning of the 2oth century respectively. More specific we will discuss Michel Foucault's arguments on the body of women since the 18th century. Thus, the strategy of hysterization of the woman's body will be our main point of reflection. In a second moment, we will try to see how a group of intellectuals has reflected on the production of these bodies and their relationship with the performance of social roles in our context until the beginning of the zoth century.

Keywords: Hysteria. Woman's body. Power. Michel Foucault.

\section{Introdução}

As mulheres e seus corpos aparecem como temáticas recorrentes do pensamento ocidental. Seria possível empreender uma análise de discursos produzidos a respeito de corpos sexuados, de mulheres, mas também de homens, permitindo considerá-los como elementos fundamentais para a percepção de muitas das disputas e transformações que estruturaram as relações sociais de seus contextos históricos. No texto em questão, nossos esforços estarão centrados na construção discursiva em torno do corpo feminino.

João Barros

UNILA. Email: joao.barros@unila.edu.br

Isadora Alves Flores

UNILA. Email: isadora94flores@gmail.com 
Veremos como a efervescência de um ambiente intelectual interventor nos hábitos e corpos da população brasileira pôde influenciar a produção intelectual médica. A partir do séc. XIX muitos profissionais demonstrar-se-iam interessados na conduta das mulheres da elite local, e de forma ainda mais expressiva à vida desregrada das mulheres de setores populares.

Antes, porém, discorreremos sobre alguns argumentos de Michel Foucault no tocante à normalização da sexualidade feminina. Privilegiando a proposta de uma histerização do corpo feminino, veremos como esse corpo pôde ser normalizado tanto do ponto de vista epistemológico, quanto do ponto de vista social. Esse duplo caráter da norma será um aspecto importante do nosso argumento, enfatizando a atuação produtiva do poder.

\section{A sexualidade normalizada em Foucault}

Michel Foucault (1926-1984), filósofo francês conhecido por suas obras e reflexões sobre a normalização da sexualidade, argumenta que a partir do sec. XVIII houve uma intensificação do poder sobre o corpo da mulher. Analisando as relações entre saber e poder neste período, Foucault assevera que os dispositivos alcançaram uma eficácia e uma produtividade antes não vista na história do Ocidente.

De modo geral, ele menciona quatro estratégias de normalização dos corpos neste período: 1) "histerização do corpo da mulher"; 2) "pedagogização do corpo da criança”; 3) "socialização das condutas procriadoras"; e 4) "psiquiatrização do prazer perverso" (FOUCAULT, 2010, p. 100-101; 1976, p. 137-138). Privilegiando os argumentos sobre a histerização do corpo da mulher, ele considera que foi

[...] um triplo processo segundo o qual o corpo da mulher foi analisado - qualificado e desqualificado - como corpo integralmente saturado de sexualidade; desse modo esse corpo foi integrado, sob o efeito de uma patologia que lhe seria intrínseca, ao campo das práticas médicas; e, por último, foi posto em comunicação orgânica com o corpo social (cuja fecundidade regulada deve assegurar), com o espaço familiar [...] e com a vida das crianças (que produz e deve garantir, por uma responsabilidade biológico-moral que dura todo o tempo da educação): a Mãe, com sua imagem negativa que é a "mulher nervosa", constitui a imagem mais visível dessa histerização (FOUCAULT, 2010, p. 100; 1976, p. 137).

Nesse trecho podemos perceber algumas consequências e características dessa estratégia de normalização. $\mathrm{O}$ corpo da mulher passa a ser revestido pelo discurso médico que o estuda e descreve tendo em conta os papeis sociais atribuídos 
às mulheres. $\mathrm{O}$ conceito de histeria será uma engrenagem discursiva fundamental dentro deste dispositivo médico que se apodera do corpo feminino.

Em outro trecho, Foucault alerta para o modo de funcionamento do dispositivo de sexualidade:

O dispositivo de sexualidade não tem como razão de ser o fato de reproduzir, mas o de proliferar, inovar, anexar, inventar, penetrar os corpos de maneira cada vez mais detalhada e controlar as populações de maneira cada vez mais global (FOUCAULT, 2010, p. 103; 1976, p. 141).

Como outro exemplo dessa estratégia de relacionar o corpo da mulher diretamente à histeria, agora falando especificamente do conceito, lemos o seguinte:

[...] a histeria nada mais é que a exacerbação de traços tradicionalmente atribuídos à mulher normal: fraqueza de vontade, hipersensibilidade, emotividade, imaginação "desregrada", "incapacidade de esforços acurados do pensamento", predomínio dos reflexos sobre a reflexão e o juízo, vaidade, leviandade, sugestibilidade (CUNHA apud ENGEL, 2018, p. 346).

Nessa perspectiva, o conceito de histeria configura um ingrediente importante para a fixação da norma e seu funcionamento. As anormalidades contidas no bojo desse conceito são trazidas à tona sobre um pano de fundo de normalidade expresso por uma norma. Neste ponto encontram-se norma e dispositivo. A primeira está circunscrita ao discursivo. Já o segundo acopla à ela elementos não discursivos. $\mathrm{O}$ dispositivo de sexualidade sempre fará menção à uma norma. Norma que, mais do que proibir, estabelecerá o que é correto, ou se quisermos, normal. Foucault argumentará no sentido de estabelecer uma relação entre norma e poder. Para ele, a fixação da norma tende a estar relacionada ao exercício do poder. Seus preceitos e/ou recomendações servirão para criar um cisão entre o normal e o patológico'. Contudo, esta não é a finalidade última. Junto dela vem a possibilidade, muitas vez levada a cabo, do exercício de um poder normalizador sobre os corpos e condutas considerados desviantes.

A norma, por conseguinte, é portadora de uma pretensão de poder. Não é simplesmente, e nem sequer, um princípio de inteligibilidade; é um elemento a partir do qual pode ser fundado e legitimado certo exercício do poder. [...] a norma [...] traz aparentados simultaneamente um princípio de qualificação e um princípio de correção (FOUCAULT, 2008, p. 57).

1 Foucault faz menção ao texto de Camguilhem, O normal e o patológico. 
Ou seja, a norma não é simplesmente uma ferramenta epistemológica. Sua função não está restrita a inteligibilidade de um caso ou ao discernimento do que é correto ou não. A qualificação e a discriminação propiciadas por seu texto e pelos parâmetros nela contidos proporcionam que o poder intervenha e sobre os corpos e condutas não alinhados ao padrão ora estabelecido. Tal ação visa uma transformação daqueles indivíduos alvo do exercício desse poder normalizador.

O dispositivo de sexualidade citado anteriormente, na figura do discurso médico, possibilita integrar ao argumento uma consideração mais geral sobre o discurso das ciências da vida. Foucault dirá o seguinte:

Esta patologia sobre o pano de fundo da normalidade, teria sido caracterizada, portanto, durante um logo tempo, todo o pensamento médico. [...] Seria impossível constituir uma ciência do vivente sem que fosse tomada em conta, como essencial ao seu objeto, a possibilidade da maldade, da morte, da monstruosidade, da anomalia e do erro (FOUCAULT, 2001, p. 1591).

Diante dessa passagem é possível mensurar como o discurso científico em geral fez uso da figura do anormal, do aberrante, do desviado, para estabelecer parâmetros, expectativas, a partir de suas normas. Essa monstruosidade e anomalia mencionadas acima serão objeto de profunda intervenção médica com o escopo de normalização.

Como exemplo de uma anomalia, a histeria da mulher, causa sempre à espera de uma oportunidade para manifestar seus efeitos, será um foco de exercício de normalização tanto do ponto de vista epistemológico (classificada, conhecida) como do ponto de vista do poder (tratada, corrigida).

Do ponto de vista epistemológico, podemos recorrer à História da Loucura na qual a histeria é abordada em seu estatuto de objeto de conhecimento médico.

Muito frequentemente a histeria foi entendida como o efeito de um calor interno que espalha através do corpo uma efervescência, uma ebulição ininterruptamente manifestada por convulsões e espasmos. Esse calor não será parente do ardor amoroso ao qual a histeria é tão frequentemente associada, nas moças à procura de marido e nas jovens viúvas que perderam o seu? A histeria é ardorosa por natureza; seus signos remetem muito mais facilmente a uma imagem do que a uma doença (FOUCAULT, 2013, p. 280).

Calor interno, convulsões, espasmos característicos de mulheres jovens e viúvas. Mesmos que o labirinto da construção médico-epistemológica não esteja ainda associado ao exercício do poder sobre o corpo da mulher, é possível entrever 
características que mais tarde serão reelaboradas na conexão saber-poder tão bem proposta em obras como Vigiar e punir, História da Sexualidade e outros textos.

O efeito irradiador provocado pela convulsão encontraria no corpo feminino um ambiente mais propício para sua ocorrência. À diferença do corpo masculino, elas teriam uma maior sensibilidade e menor coesão interna entre seus órgãos. Tais características proporcionariam caminhos para que a histeria se espalhasse rapidamente e de forma também mais capilar.

Quanto mais facilmente penetrável for o espaço interior, mais frequente será a histeria e múltiplos serão os seus aspectos; mas se o corpo é firme e resistente, se o espaço interior é denso, organizado e solidamente heterogêneo em suas diferentes regiões, os sintomas da histeria são raros e seus efeitos permanecerão simples. Não é exatamente isso que separa a histeria feminina da masculina [...]? (FOUCAULT, 2013, p. 287)

Organização e solidez seriam características do corpo masculino que o protegeriam dessa moléstia. Por natureza, a mulher estaria mais susceptível a ataques histéricos por uma debilidade de sua própria carne: penetrável e espaçada interiormente.

Essas características do corpo feminino em muitos casos foram resumidas a um predomínio do útero e suas atividades sobre o cérebro. "A loucura que habitaria o corpo das mulheres, cujo pequeno cérebro seria dominado pelo útero, exprime, dessa maneira sua desordem interior, sua ausência de razão" (SWAIN, 2013, p. 225). Esse suposto domínio do cérebro pela atividade uterina seria um dos grandes postulados da Psiquiatria no séc. XIX. Tal conclusão sobre o corpo da mulher daria margem para o desenvolvimento e o uso de procedimentos altamente invasivos e violentos. As palavras de Margareth Rago nos ajudam a entender a gravidade da situação:

[...] a inferioridade biológica das mulheres era usada para explicar a incidência da histeria entre as mulheres, e como o tratamento usado no hospital da Salpêtrière, em Paris, era centrado nos ovários, inventaram-se instrumentos mecânicos para comprimilos ou envolve-los com gelo. Já na Alemanha, utilizavam-se métodos mais radicais, como a ovariectomia e a cauterização do clitóris (RAGO, 2013, p. 239-240).

De um efeito natural a um castigo moral, a histerização do corpo feminino poderia percorrer todo um périplo concernente ao diagnóstico e ao tratamento da histeria. Com isso Foucault nos ajuda a entender esse corpo como objeto de saber e também de poder. A partir da concepção desse corpo feminino prenhe de uma "eterna possibilidade de histeria”, a Medicina do séc. XVIII construiu toda uma rede 
argumentativa e conceitual para circunscrevê-lo nesses moldes (FOUCAULT, 2013, p. 291).

Dita construção chegaria ao séc. XIX muito mais elaborada e com efeitos notadamente fortes no desenvolvimento do saber Psiquiátrico. $\mathrm{O}$ envolvimento do corpo feminino por esse novo discurso possibilitaria o encarceramento de uma infinidade de mulheres que fugiram à norma. Como nos explica Tânia Swain,

O século XIX realiza o internamento geral das mulheres no Ocidente, sem muros, sem asilo, sem prisão: é um internamento na exclusão do espaço público e dos direitos cívicos, num conjunto de leis que as marcam do selo da fraqueza, da ignorância, das proibições mais diversas: de trabalhar, de estudar, de sair, de escrever, de se expressar, enfim (SWAIN, 2013, p. 230).

Aquela que quisesse escapar à norma, ao estabelecido como natural da 'verdadeira mulher' poderia cair em uma rede discursiva que ensejava uma punição disfarçada de tratamento, ou um tratamento punitivo por estar contrariando sua própria natureza.

Vemos então, como a histerização do corpo feminino foi possível devido à grande frouxidão epistemológica, por um lado, mas também à utilização da norma por outro. Esta não seria apenas uma construção discursiva. Marcava também a fronteira entre o normal e o anormal em contraste com um "fundo de regularidade administrativa, [...] de obrigações familiares ou [...] de normatividade política e social” (FOUCAULT, 2008, p. 152). Ou seja, não há apenas uma relação com a verdade, mas também uma ingerência sobre todas as condutas possíveis desconformes, seja do ponto de vista administrativo, familiar, político ou social. Sem dúvida uma ferramenta de exercício de poder sobre os corpos.

No próximo tópico veremos mais especificamente como essas tendências e sedimentações da pesquisa e prática médicas no contexto europeu foram recebidas em solo brasileiro. Não temos a pretensão de defender uma relação de causalidade direta. Nosso objetivo será apenas arrolar algumas fontes que retomam esse debate sobre a normalização do corpo feminino a partir de alguns elementos expostos acima.

\section{Corpos e papeis sociais no Brasil}

A produção de imagens sobre o feminino não foi uma novidade do período compreendido entre os sécs. XVIII e XX. Tendo mobilizado ao longo de séculos inúmeros esforços de significação e representação, as mulheres e seus corpos aparecem como temáticas recorrentes do pensamento ocidental (LAQUEUR, 1992; MARTINS, 2004; SCOTT, 1994,1995). Compreendemos, portanto, que a análise de discursos produzidos a respeito de corpos sexuados, de mulheres, mas também de homens, permite considerá-los como elementos fundamentais para a percepção de 
muitas das disputas e transformações que estruturaram as relações sociais de seus contextos históricos.

Adotamos, portanto, uma abordagem da mediação proposta por faits divers ${ }^{2}$ da experiência feminina no início do século XX que recorre à conceituação de gênero proposta pela historiadora estadunidense Joan Wallach Scott (1994; 1995). De maneira que, ao apreendermos o gênero como um "elemento constitutivo das relações sociais baseado nas diferenças percebidas entre os sexos" (SCOTT, 1995, p. 86), não objetivamos uma negação de toda e qualquer diferença entre os corpos sexuados, mas sim, afirmar a historicidade implicada na construção dos significados atribuídos a tais diferenças. Afinal, segundo nos subsidia Scott (1995) em seu ensaio "Gênero uma categoria útil para análise histórica", o gênero como um saber, uma forma "de significar as relações de poder" se verificaria uma "dimensão decisiva da organização da igualdade e desigualdade” (SCOTT, 1995, p.26).

Conforme a historiadora nos aportaria no prefácio de seu livro Gender and Politics of History, os sentidos construídos aos gêneros masculino e feminino

[...] variam de acordo com as culturas, os grupos sociais e no tempo, já que nada no corpo, incluídos aí os órgãos reprodutivos femininos, determina univocamente como a divisão social será definida. Não podemos ver a diferença sexual a não ser como função de nosso saber sobre o corpo e este saber não é "puro", não pode ser isolado de suas relações numa ampla gama de contextos discursivos (SCOTT, 1994, p.13).

A despeito disso, com o intuito de contextualizar algumas das significações investidas a diferença sexual no início do século XX, consideramos alguns dos pressupostos de Thomas Laqueur (1990) em seu livro Making Sex. Body and Gender from the Greeks to Freud. Esse historiador norte-americano analisa o percurso histórico da elaboração científica da distinção entre os sexos biológicos tal qual a concebemos na atualidade. Segundo o autor, contrapondo o antigo modelo de conhecimento sobre o corpo humano baseado da homologia sexual3, a concepção de dois sexos biológicos com diferenças físicas irredutíveis, teria emergido há pouco mais de duzentos anos (LAQUEUR,199o, p.149-245). Assim sendo, teria sido no século XVIII, que:

\footnotetext{
2 A categoria faits divers foi cunhada ... . Para mais detalhes sobre o conceito, remetemos ao texto...

3 Anteriormente era predominante um modelo teórico sobre o corpo humano no qual o que hoje chamamos de diferença sexual era percebido em termos hierárquicos e explicado por princípios cósmicos. [...]. Neste pensamento o que diferenciava o homem da mulher não eram as características sexuais do corpo, mas uma noção de perfeição baseada no calor vital. O corpo feminino era a expressão da imperfeição porque seus órgãos sexuais eram invertidos, por não ter calor suficiente para exteriorizálos como o homem. Assim, foi construída uma poderosa imagem do corpo feminino que perdurou até mesmo no século XIX, época do predomínio das idéias sobre as diferenças radicais entre os sexos: é a imagem da mulher imperfeita - a versão imperfeita do homem, tomado como medida e padrão da perfeição humana e de todos os seres vivos (MARTINS, 2004, p.27)
} 
Organs that had shared a name - ovaries and testicles - were now linguistically distinguished. Organs that had not been distinguished by a name of their own - the vagina, for example - were given one. Structures that had been thought common to man and woman - the skeleton and the nervous system - were differentated so a to correspond to the cultural male and female (LAQUEUR, 1990, p.149).

Não somente, ao longo desse processo:

As the natural body itself became the gold standard of social discourse, the bodies of women - the perennial other - thus became the battleground for redefining the ancient, intimate, fundamental social relation: that of woman to man. Women's bodies in their corporeal, scientifically accessible concreteness, in the very nature of their bones, nerves, and, most important, reproductive organs, came to bear an enormous new weight of meaning. Two sexes, in other words, were invented as a new foundation for gender (LAQUEUR, 1990, p.149-150).

Numa perspespectiva de longa duração e compreendendo que as contemporâneas construções sociais referentes aos gêneros estão atreladas também ao processo de teorização das distinções entre os dois sexos biológicos, Laquear (1990, p.63-149) não nega a hierarquização presente nos modelos anteriores a tal concepção. Ressalva, nesse sentido, que a diferenciação sexual colocada em curso a partir de meados do século XVIII não deve ser encarada simplesmente como um desdobramento natural do progresso da ciência, mas compreendida de forma situacional, ou seja, também considerando as disputas nas relações entre gênero e poder (LAQUEUR, 1990, p.11). De forma que:

The ways in which sexual difference have been imagined in the past are largely unconstrained by what was actually known about this or that bit of anatomy, this or that physiological process, and derive instead fom the rhetorical exigencies of the moment (LAQUEUR, 1990, p.11).

Embasada pelas percepções de Laquer (1990), Ana Paula Vosne Martins (2004) em seu livro Visões do Feminino: a medicina da mulher nos séculos XIX e XX, enfatiza o papel da medicina e das ciências biológicas nos esforços daquilo que concebe como uma inventariação das diferenças sexuais no contexto nacional. Alinhada com a advertência de Laqueur (1990) das implicações sociais e culturais desses exercícios interpretativos, Martins (2004) também sustenta que a partir do século XVIII, cientistas teriam contribuído para a legitimação e justificação das desigualdades de gênero na vida pública e privada ao teorizarem e interpretarem as singularidades do 
corpo feminino, suas patologias e sistema reprodutivo (MARTINS, 2004, p.31). Nas palavras da autora:

Para onde olhavam, os homens da ciência do século XVIII só viam um avolumar-se de diferenças, fosse entre os minerais, fosse entre as plantas e os animais, fosse entre os seres humanos. Entre estes, a nova ciência biológica do sexo mostrava como homens e mulheres eram diferentes e como as diferenças físicas e até mesmo químicas eram determinantes na vida social de ambos. Fortaleciase a convicção de que à forma correspondia a função, só que este princípio anatomofisiológico, ao ser ressignificado socialmente, estabelecia uma relação indelével entre o corpo e os papéis sociais. No entanto, as diferenças humanas não se restringiam ao sexo. Na mesma época, os naturalistas davam os primeiros passos para explicar as diferenças raciais, constituía-se um outro conjunto de discursos científicos voltados para a questão da variação humana (MARTINS, 2004, p.32).

Com efeito, Martins (2004) interpreta tais processos como resultantes de um amplo empreendimento intelectual de inventário das diferenças humanas, pelo qual:

Sexo e raça passaram a ser categorias biológicas cada vez mais interrelacionadas no discurso científico do final do século XVIII em diante, numa nítida resposta da comunidade científica às pressões sociopolíticas colocadas pela questão das desigualdades de gênero e pelo colonialismo. Conforme Pierucci (1999), o final do século XVIII foi pródigo na produção das diferenças, especialmente por parte do discurso de intelectuais conservadores. Procedese, portanto, inventariando as diferenças para, posteriormente, nos embates políticos, rejeitá-las no interior de formulações discursivas sexistas e racistas (MARTINS, 2004, p.33).

Não somente, segundo Martins (2004) o interesse científico pelo inventário das diferenças humanas avançaria ao longo do século XIX, período no qual a produção científica sobre raça e sexualidade se intensificaria de forma expressiva. Nesse contexto, médicos e cientistas teriam mantido "suas buscas a respeito das diferenças sexuais, especialmente a respeito das diferenças do corpo feminino" (MARTINS, 2004, p.36). Formular-se-ia a partir daí “[...] o conhecimento necessário para subsidiar outros discursos igualmente interessados na mulher e na sua diferença" (MARTINS, 2004, p.36).

Segundo a autora:

Este saber acumulado e constantemente renovado ao longo de todo o século XIX não ficou restrito aos bancos das faculdades 
de medicina e às publicações especializadas. A escrita masculina a respeito da diferença feminina é um notável exemplo da apropriação do saber médico e científico pelos intelectuais envolvidos com a questão da mulher, traduzindo para o público leigo as descobertas dos doutores (MARTINS, 2004, p.43).

De forma que, extrapolando os limites de laboratórios e clínicas e, portanto, difundida também entre intelectuais dos mais variados campos: filósofos, sociólogos, psicanalistas e literatos, percebe-se a vitalidade de uma construção ambígua da natureza feminina ao longo do século XIX e XX (ENGEL, 20o6, p.333; MARTINS, 2004, p.41). Natureza essa, ora redimida pela sua "natural" função reprodutora e, como tal, exaltada pela sua suposta aptidão para a maternidade. Ora condenada, compreendida como fator engendrador da maldade e do vício, da desordem social, facilmente ultrapassando "a tênue fronteira entre a normalidade e a patologia, como tão incansavelmente os médicos vão alertar ao abordar temas como masturbação e, prostituição" (MARTINS, 2004, p.41).

Nas palavras de Magali Gouveia Engel (2011) em "Psiquiatria e Feminilidade", capítulo de sua autoria do livro História das Mulheres no Brasil:

Vista como uma soma desarrazoada de atributos positivos e negativos, cujo resultado nem mesmo os recursos científicos cada vez mais sofisticados poderiam prever, a mulher transformava-se num ser moral e socialmente perigoso, devendo ser submetida a um conjunto de medidas normatizadoras extremamente rígidas que assegurassem o cumprimento do seu papel social de esposa e mãe; o que garantiria a vitória do bem sobre o mal, de Maria sobre Eva. Se a mulher estava naturalmente predestinada ao exercício desses papéis, a sua incapacidade e/ou recusa em cumpri-los eram vistas como resultantes da especificidade da sua natureza e, concomitantemente, qualificadas como antinaturais. Sob a égide das incoerências do instinto, os comportamentos femininos considerados desviantes - principalmente aqueles inscritos na esfera da sexualidade e da afetividade - eram vistos ao mesmo tempo e contraditoriamente como pertinentes e estranhos à sua própria natureza. Nesse sentido, a mulher era concebida como um ser cuja natureza específica avizinhava-se do antinatural. (ENGEL, 2011, p.332)

Diante dessa ambiguidade, o pensamento masculino a respeito da mulher teria, de forma geral, se dividido em duas correntes predominantes durante todo o século XIX: enquanto alguns acreditavam que "a educação correta e bem orientada da menina, visando à boa formação moral e à contenção do corpo, iria resultar na mulher saudável, de caráter dócil e submissa ao seu esposo" (MARTINS, 2004, p.42) e outros, "desconfiados da natureza ambígua da mulher, temiam a sexualidade feminina e seus efeitos desestabilizadores”. Tendências que Martins (2004) verifica 
tanto no discurso científico e filosófico "quanto na literatura, nas artes plásticas e nos textos de caráter sociológico, tão típicos da segunda metade do século" (MARTINS, 2004, p.42). Para a autora de "Comte a Engels, de Michelet a Schopenhauer, de Flaubert a Zola, além da extensa produção médica que atravessa o século XIX, nunca se falou tanto da mulher", o que por sua vez expressaria "o problema da definição da mulher para os homens cultos da sociedade europeia” (MARTINS, 2004, p.42).

Tal problema que não ocupava apenas os homens cultos europeus, tendo em vista como empreendimentos intelectuais com esse propósito e a partir de interpretações das supostas características intrínsecas dos sexos biológicos, também marcaram o contexto brasileiro. De tal modo que, já a partir da metade do século XIX, verificar-se-ia a incidência desses esforços interpretativos, sobretudo entre as classes altas e médias (SOIHET, 1989, p. 40; ENGEL, 2004, p. 42; MARTINS, 2004, p. 177), auxiliando a emergência de um clima intelectual de caráter interventor nos hábitos e corpos da população brasileira. Médicos demonstravam-se desfavoráveis à notável reclusão das mulheres da elite local, e de forma ainda mais expressiva à vida “desregrada” das mulheres de setores populares (MARTINS, 2004, p. 177; ESTEVES, 1989 p. 27-43).

Com efeito, ao observamos a bibliografia voltada à análise da experiência histórica de mulheres em finais do século XIX e início do XX (ESTEVES, 1989; SOIHET, 1989; ARAÚJO, 1995) percebemos que, como projetos explicativos da sociedade, as interpretações biologizantes dos sexos, teriam exercido um papel importante na produção/legitimação das atribuições sociais e até mesmo legais, de homens e mulheres cariocas considerados ordeiros. Com o selo da medicina, não somente foi divulgada uma suposta disposição biológica das mulheres para com os cuidados de seus filhos, mas segundo nos evidencia a pesquisadora Rachel Soihet (1989), em seu livro Condição feminina e formas de violência: mulheres pobres e a ordem urbana 1890-1920, os doutores do início do século XX também postulariam cientificamente a impropriedade do exercício da mulher de qualquer outra função. Difundindo uma imagem do feminino que:

[...] destacava a sua fragilidade física, de onde decorriam sua delicadeza e debilidade moral. Por injunções da natureza, era considerada como inferior ao homem, inferioridade que se manifestava pelo predomínio das "faculdades afetivas", tornando-a mais "sentimental" que "filósofa". Sua imaginação viva, fértil, mas fugaz indispunha-a para os trabalhos do espírito e para as atividades intelectuais (SOIHET,1989, p. 114).

A despeito dos empreendimentos científicos pela definição do papel social feminino, de modo geral, a realidade concreta da maioria das mulheres fugia ao olhar desses intelectuais (SOIHET, 1989, p.166). De forma que esses homens da ciência nem sempre consideravam a pluralidade de vivências femininas em relação as suas diversas localizações na estrutura social. A título de exemplo dos pontos cegos 
desses doutores, Soihet (1989) constata que, ainda que divulgassem a impropriedade feminina ao mundo laboral, na época:

[...] a utilização do trabalho da mulher se constituía num elemento essencial na organização social e na acumulação da riqueza tanto do ponto de vista do trabalho doméstico, como na sua participação no processo produtivo (SOIHET,1989, p. 178).

Com efeito, "apesar de trabalharem e muito", sobretudo em atividades tradicionalmente "femininas" como "lavadeiras, costureiras, rendeiras, serviços domésticos, prostituição e, também, no pequeno comércio de bens produzidos em casa" (SOIHET, 1989, p.169), a rotina laboral dessa parte da população era bastante invisível. Nesse contexto histórico, subsidia-nos Soihet (1989) que, não somente muitas dessas ocupações não constavam nos censos oficiais, mas também:

Por força da ideologia de que a função essencial da mulher prende-se ao lar, muitas mulheres, mesmo exercendo uma outra atividade, ao serem inquiridas, declaram apenas o exercício do serviço doméstico, conforme foi por nós observado em alguns processos criminais (SOIHET,1989, p. 169)

Nesse sentido, como nos indica a análise da literatura das experiências femininas desse período (ESTEVES, 1989; SOIHET, 1989, p.191, CHALHOUB, 2004, p.173-213) vigorava o imperativo da luta cotidiana pela sobrevivência, fato esse que impediu os processos de dissidência e mesmo ressignificação dos modelos de feminilidade oriundos das camadas médias e altas. Todavia, as experiências afetivas, sexuais e mesmo laborais, entre mulheres pertencentes aos setores populares demonstram-se significadas, também em virtude dos discursos que envolviam o feminino, circunscrevendo-o ao mundo privado, dos sentimentos e do lar.

\section{Conclusão}

Tendo em consideração os argumentos expostos é possível considerar que o discurso científico em geral, e médico em particular, fez uso da figura do anormal, do aberrante, do desviado, para estabelecer parâmetros e expectativas a partir de suas normas. Assim sendo, é possível considerar que a monstruosidade e a anomalia características das condutas desviantes foram objeto de profunda intervenção médica objetivando a normalização.

A partir dos textos de Foucault foi possível ter contato com uma estratégia de histerização do corpo feminino. Esse corpo foi saturado de sexualidade e integrado ao campo das práticas médicas por meio do uso de uma patologia que lhe seria 
intrínseca. Daí, o uso desse discurso médico para a legitimação de papeis sociais que lhe seriam natos, foi apenas um passo. Para a efetivação desses passos, a norma foi um ingrediente fundamental. Ao mesmo tempo ferramenta epistemológica e instrumento de poder, a norma possibilitaria a inteligibilidade e o exercício do poder sobre corpos e condutas com vistas à normalização.

Para abordar a realidade brasileira, partimos dos argumentos de Martins, sustentando a participação de cientistas na legitimação ejustificação das desigualdades de gênero na vida pública e privada no século XVIII, ao teorizarem e interpretarem as singularidades do corpo feminino, suas patologias e sistema reprodutivo. Da mesma maneira, Engel colabora nesta visão de que a escrita masculina a respeito da diferença feminina é um bom exemplo da apropriação do saber médico por diversos setores da intelectualidade.

\section{Referências}

ARAÚJO, Rosa Maria Barboza de. A vocação do Prazer: a cidade e a família no Rio de Janeiro republicano. Editora Rocco. Rio de Janeiro, 1995.

CHALHOUB, Sidney. Trabalho, Lar e Botequim: o cotidiano dos trabalhadores no Rio de Janeiro da Belle Époque. Campinas: Editora da Unicamp, 2001.

ENGEL, Magali Gouveia. "Psiquiatria e feminilidade”. IN: PRIORE, Mary Del (org). História da Mulheres no Brasil. 3를 ed. São Paulo: Contexto, 2018.

. Paixão, crime e relações de gênero (Rio de Janeiro, 1890-1930). Topoi (Rio de Janeiro), v. 1, n. 1, p. 153-177, 2000.

Meretrizes e doutores: saber médico e prostituição no Rio de Janeiro (1840-1890). São Paulo: Brasiliense, 2004.

ESTEVES, Martha de Abreu. Meninas Perdidas: os populares e o cotidiano do amor no Rio de Janeiro da Belle Époque. Rio de Janeiro: Editora Paz e Terra, 1989.

FOUCAULT, Michel. Dits et écrits II. Paris: Gallimard, 2001.

FOUCAULT, Michel. História da loucura na época clássica. Trad. José Teixeira Coelho Neto. São Paulo: Perspectiva, 2013.

FOUCAULT, Michel. Historia de la sexualidade 1. Trad. Ulises Guiñazú. Buenos Aires: Siglo Veintiuno, 2010.

FOUCAULT, Michel. Histoire de la sexualité I. Paris: Gallimard, 1976. 
FOUCAULT, Michel. Los anormales. Trad. De Horacio Pons. Buenos Aires : Fondo de Cultura Económica, 2008.

LAQUEUR, Thomas Walter. Making sex: Body and gender from the Greeks to Freud. Harvard University Press, 1990.

MARTINS, Ana Vosne. Visões do feminino: a medicina da mulher nos séculos XIX e. XX. Rio de Janeiro: Editora FIOCRUZ, 2004.

RAGO, Margareth. Foucault, a histeria e a aranha. In: MUCHAIL, Salma Tannus; FONSECA, Márcio Alves da; Veiga-Neto, Alfredo (Orgs.). O mesmo e o outro: 50 anos da História da loucura. Belo Horizonte: Autêntica, 2013, p. 235-246.

SCOTT, Joan Wallach. Prefácio a Gender and Politics of History. Cadernos Pagu: Desacordos, desamores e diferenças. Campinas: Pagu - Núcleo de Estudos de Gênero, n.3, 1994.

Gênero: uma categoria útil de análise histórica. Educação \& Realidade. Porto Alegre, vol. 20, no 2, jul./dez. 1995.

SOIHET, Rachel. Condição Feminina e Formas de Violência: Mulheres Pobres e Ordem Urbana 1890-1920. Rio de Janeiro, Forense Universitária. 1989.

SWAIN, Tânia Navarro. Mulheres indômitas e malditas: a loucura da razão. In: MUCHAIL, Salma Tannus; FONSECA, Márcio Alves da; Veiga-Neto, Alfredo (Orgs.). O mesmo e o outro: 50 anos da História da loucura. Belo Horizonte: Autêntica, 2013, p. 223-245. 